\title{
Behaviour of unbonded post-tensioned precast concrete coupled walls under lateral loads
}

\author{
T. C. Aragon \& B. D. Weldon \\ New Mexico State University, USA
}

\begin{abstract}
This paper presents an analytical investigation of the non-linear behaviour of coupled concrete walls using unbonded post-tensioned precast concrete coupling beams under monotonic lateral loading. Coupling of the walls is achieved by post-tensioning the beams and walls together at the floor and roof levels. Steel top and seat angles are used at the beam-to-wall interfaces and are designed to yield and provide energy dissipation during an earthquake. As the structure is laterally displaced, the non-linear deformations occur primarily as a result of the opening of gaps at the beam-to-wall interfaces. This system offers many advantages over monolithic cast-in-place beams such as simpler detailing, the ability to undergo large lateral displacement with little damage to the structure, and self-centring capabilities. To assess how the system behaviour can be controlled by design, structural parameters such as the beam and wall geometry, the amount of post-tensioning, and the top and seat angle properties are varied. The effect of these parameters on the lateral strength and deformation capacities and demands are investigated through non-linear pushover analyses. Results demonstrate that this innovative system can provide excellent stiffness, strength, and ductility in a properly designed multi-story structure.
\end{abstract}

Keywords: concrete, coupled walls, post-tensioning, seismic analysis, precast concrete.

\section{Introduction}

The lateral strength and stiffness of reinforced concrete walls serving as the primary lateral load resisting system can significantly be increased by connecting the walls together with coupling beams at the floor and roof levels (e.g., Harries et al. [1]). As a lateral load is applied to the coupled wall system, shear forces are 
transferred through the coupling beams forming an axial tension-compression couple. The overturning moments are partially resisted by this couple rather than solely by the individual flexural action of the walls. Coupled walls provide a means in which energy dissipation can be distributed over the entire height of the structure, whereas in individual flexural walls, the dissipation is concentrated primarily in the first story. If appropriately detailed, coupled wall systems can exhibit minimal damage and negligible permanent deformations resulting in a suitable design for structures located in regions of high seismicity.

Monolithic cast-in-place reinforced concrete coupling beams with conventional longitudinal and transverse reinforcement have been shown to fail in the form of diagonal tension or shear sliding under lateral loads. To overcome these failures and improve the seismic response of a coupled wall system, Paulay and Binney [2] proposed the use of diagonally reinforced beams. This type of detailing, however, can be difficult to construct due to congestion at the centre of the beam and at the wall faces as the reinforcement crosses the beam-to-wall interface (as vertical steel in the wall is often concentrated in these areas). This system can also result in deep beams as the diagonal reinforcement oftentimes requires a large angle of inclination (i.e., angle between the diagonal bars and the longitudinal axis of the coupling beam) in order for the system to be effective.

As an alternative to reinforced concrete coupling beams, hybrid coupled wall systems where steel beams are embedded into reinforced concrete walls have also been introduced (e.g., Gong and Shahrooz [3]). More recent research investigated the use of unbonded post-tensioned coupled wall structures with steel beams that are not embedded into the walls. (Kurama and Shen [4, 7], Shen et al. [5], Kurama et al. [6] Shen and Kurama [8]). This system has the ability to achieve a similar initial stiffness as an embedded coupled wall system with the same dimensions due to the post-tensioning. Unbonding the post-tensioning tendons in the system leads to two major advantages: (1) it results in a uniform strain distribution in the tendons, and thus, significantly delays the yielding of the post-tensioning steel; and (2) it significantly reduces the amount of damage due to cracking in the wall and beam concrete because the tensile stresses transferred to the concrete are reduced. The system also offers a means in which self-centring (i.e., the ability of the structure to return to its original position upon unloading) of the structure can occur.

Weldon and Kurama [9-12], extended upon the use of unbonded posttensioning, but rather than steel beams, precast concrete coupling beams were used to couple cast-in-place concrete structural walls. This system eliminates the need for diagonal reinforcement and monolithic action as no reinforcement crosses the beam-to-wall interface. This innovative system also reduces the amount of shear reinforcement in the beams and the precast plant production of the beams allows for better quality control compared to cast-in-place systems. Precast concrete beams were explored because of the following advantages they have over steel coupling beams: (1) a reduced amount of post-tensioning hardware and operations because of the central location of the posttensioning strands; (2) better fire and environmental protection for the post-tensioning hardware due to the surrounding concrete; (3) improved sliding 
shear resistance at the beam-to-wall interface as a result of the higher concreteagainst-concrete friction resistance; and (4) single trade construction. Half-scale single-floor level subassemblies were investigated experimentally and analytically to examine the non-linear behaviour of the system under lateral loading. The system exhibited excellent lateral strength, stiffness, ductility, and energy dissipation characteristics under large reversed-cyclic loading. The research described in this paper uses the verified subassembly analytical models from Weldon and Kurama [9] to investigate a multi-story unbonded posttensioned precast concrete coupled wall system. Parametric non-linear static monotonic (i.e., pushover) analyses are conducted using the analytical model to better understand the behaviour of the multi-story system and how different structural parameters (e.g., beam depth) affect the response of the multi-story structure.

\section{The unbonded post-tensioned precast coupling wall system}

Figure 1(a) shows an example of a typical eight-story coupled wall structure with the coupling beams located at the floor and roof levels. An isolated single-floor level unbonded post-tensioned precast concrete coupling beam subassembly and typical cross-section is shown in Figure 1(b). The subassembly includes the precast coupling beam and the adjacent cast-in-place reinforced concrete walls at a floor level as indicated by the shaded region in Figure 1(a).

Coupling of the reinforced concrete walls is achieved by post-tensioning the walls and the beams together using high-strength multi-strand tendons as

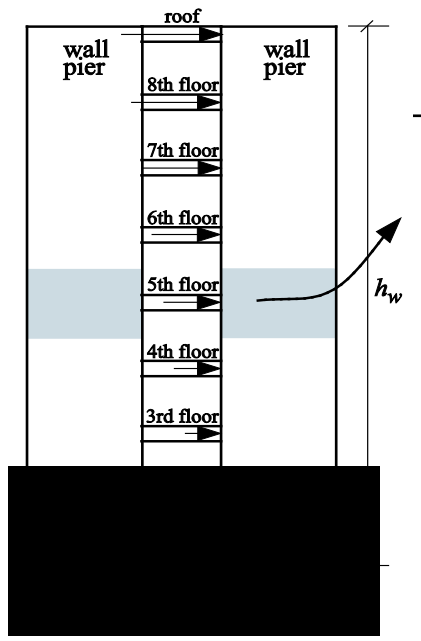

(a)
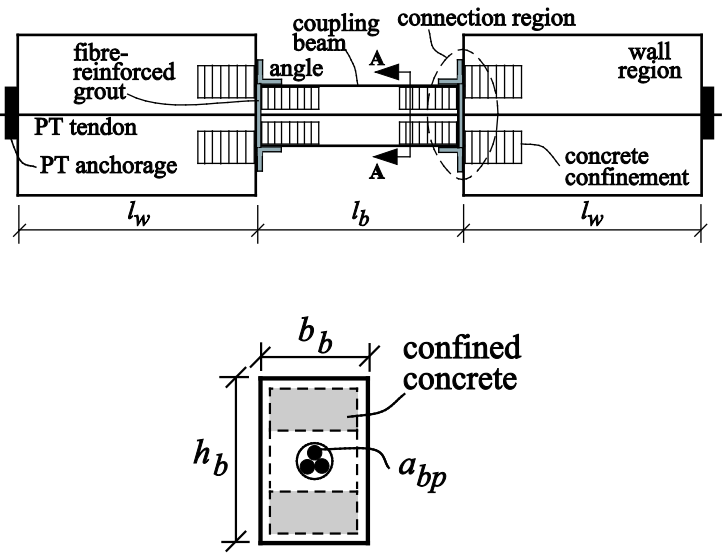

section at A-A

(b)

Figure 1: (a) Multi-story coupled wall system; (b) unbonded post-tensioned subassembly at a floor level (adapted from Weldon and Kurama [11]). 
described in Weldon and Kurama [12]. Unbonded post-tensioning is achieved by placing the post-tensioning tendons in ungrouted oversized ducts and anchoring the tendons only at the outer ends of the walls.

Top and seat angles are located at the beam-to-wall connection regions. These angles are designed to yield and provide energy dissipation in the system during a seismic event. These angles, if heavily damaged during an earthquake, can easily be replaced. They, therefore, serve as sacrificial elements in the system and the need to replace the coupling beams and/or walls after the earthquake is eliminated. The angles also provided redundancy in support of the beam and can serve as temporary supports during construction.

Confinement is placed in the contact regions where large compressive stresses are expected to occur to prevent concrete crushing of the beams and walls. These stresses are developed as a lateral load is applied and the system begins to deform as shown in the idealized exaggerated deformed shape in Figure 2(a) (with the load being applied from left to right).

As the lateral load is applied to the structure, the initial post-tensioning force in the system is eventually overcome and gaps begin to open at the beam-to-wall interface. The non-linear deformations of the beam occur mostly as a result of this gap opening. The post-tensioning force controls the width of the gaps and upon unloading, the post-tensioning provides a restoring force that closes the gaps reducing the residual stresses and displacements.

The coupling forces at the beam ends, $V_{b}$, are formed from a large diagonal compression strut that is developed in the beam as a result of the post-tensioning forces as shown in Figure 2(b). The magnitude of the coupling forces can be controlled by varying the beam depth, $h_{b}$, beam length, $l_{b}$, and the initial posttensioning force, $\mathrm{P}_{b p i}$ (note that the angle forces are not included).

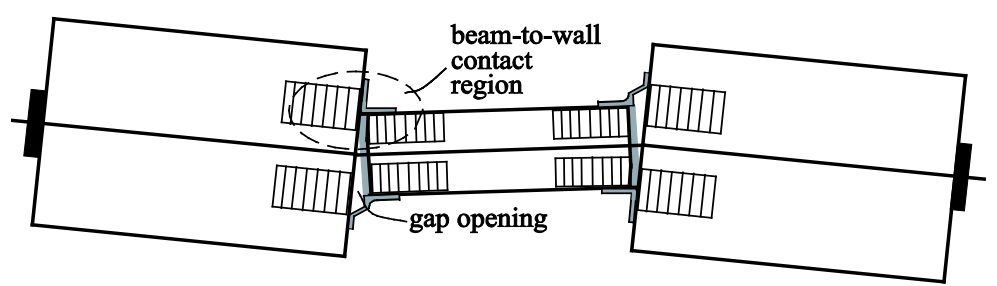

(a)

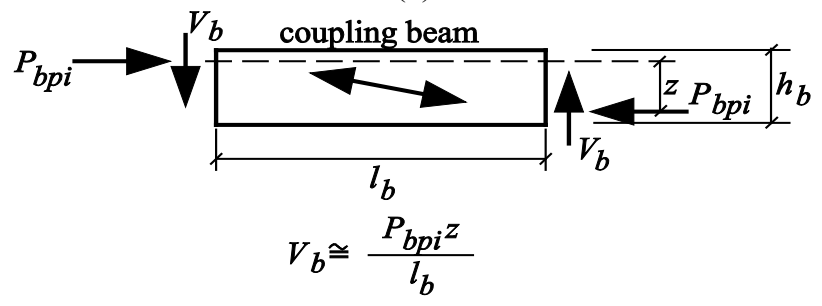

(b)

Figure 2: (a) Idealized deformed subassemly; (b) coupling beam forces. 


\section{Prototype structure}

This section describes the properties of the multi-story unbonded post-tensioned precast concrete coupled wall structure prototype system. A description of the analytical model is then discussed.

\subsection{Structural properties}

Two identical monolithic cast-in-place reinforced concrete walls based on the walls designed in Shen et al. [13] are used for this investigation. The prototype structure was designed for a region of high seismicity (e.g., Los Angeles) and a site with a "stiff" soil profile. The floor and roof slabs are not considered because the objective of this research is to investigate the behaviour of isolated coupled walls under lateral loads.

The first story has a height of $4.88 \mathrm{~m}$ and each of the upper stories have a height of $3.96 \mathrm{~m}$ resulting in a total height, $h_{w}$, of $32.6 \mathrm{~m}$. The thickness, $t_{w}$, of the walls is $356 \mathrm{~mm}$ (uniform throughout the height of the structure) and each wall has a length, $l_{w}$, of $4.88 \mathrm{~m}$. It is assumed that adequate concrete confinement is provided by spiral reinforcement at the base of the structure.

The precast concrete coupling beams have a rectangular cross-section with a length, $l_{b}$, of $2286 \mathrm{~mm}$, a depth, $h_{b}$, of $711 \mathrm{~mm}$, and a thickness, $t_{b}$, of $356 \mathrm{~mm}$. The beam is assumed to be adequately designed and detailed with transverse steel reinforcement to prevent diagonal tension failure.

To connect the beams and walls together and post-tension the beams, three ASTM A 416 low-relaxation tendons are used at each floor level. The total posttensioning area on each floor is $\Sigma a_{b}=1680 \mathrm{~mm}^{2}$ and the tendons are prestressed to $0.5 f_{\text {bpu }}$.

U.S. L8X8X1/2 top and seat angles $\left(f_{a y}=245 \mathrm{MPa}\right)$ are used at the beam-towall connection regions. The angles have a length equal to the thickness of the coupling beam, $l_{a}=356 \mathrm{~mm}$.

A model developed by Mander et al. [14] is used to determine the stressstrain relationship of the unconfined and confined concrete in the walls and beams. The mild steel reinforcement stress-strain relationship in the walls is based on experimental results as described in Paulay and Priestley [15]. The bonded mild steel reinforcement in the coupling beam is not represented in the model as it does not contribute to the lateral resistance of the structure. The force-deformation relationship of the steel angles is determined using methods developed by Kishi and Chen [16] and Lorenz et al. [17]. The properties of the confined and unconfined concrete in the beams and walls, the mild steel reinforcement in the beams and walls, and the post-tensioning strands are listed in Tables 1 through 4. 
Table 1: $\quad$ Prototype wall concrete material properties.

\begin{tabular}{|l|c|l|c|}
\hline \multicolumn{2}{|c|}{ Unconfined concrete } & \multicolumn{2}{c|}{ Spiral confined concrete } \\
\hline $\begin{array}{l}\text { Linear elastic stiffness, } \\
E_{w u}\end{array}$ & $30441 \mathrm{MPa}$ & $\begin{array}{l}\text { Linear elastic stiffness, } \\
E_{w c}\end{array}$ & $30441 \mathrm{MPa}$ \\
\hline Maximum strength, $f_{w u}$, & $41.4 \mathrm{MPa}$ & Maximum strength, $f_{w c}$ & $53.9 \mathrm{MPa}$ \\
\hline $\begin{array}{l}\text { Strain at maximum } \\
\text { strength, } \varepsilon_{w u}\end{array}$ & 0.002 & $\begin{array}{l}\text { Strain at maximum } \\
\text { strength, } \varepsilon_{w c},\end{array}$ & 0.0052 \\
\hline Ultimate strain, $\varepsilon_{w u u}$ & 0.003 & Ultimate strain, $\varepsilon_{w c u}$ & 0.0128 \\
\hline
\end{tabular}

Table 2: $\quad$ Prototype beam concrete material properties.

\begin{tabular}{|l|c|l|c|}
\hline \multicolumn{2}{|c|}{ Unconfined concrete } & \multicolumn{2}{c|}{ Spiral confined concrete } \\
\hline $\begin{array}{l}\text { Linear elastic stiffness, } \\
E_{b u}\end{array}$ & $30441 \mathrm{MPa}$ & $\begin{array}{l}\text { Linear elastic stiffness, } \\
E_{b c}\end{array}$ & $30441 \mathrm{MPa}$ \\
\hline Maximum strength, $f_{b u}{ }^{\prime}$ & $41.4 \mathrm{MPa}$ & Maximum strength, $f_{b c}$, & $109.6 \mathrm{MPa}$ \\
\hline $\begin{array}{l}\text { Strain at maximum } \\
\text { strength, } \varepsilon_{b u},\end{array}$ & 0.002 & $\begin{array}{l}\text { Strain at maximum } \\
\text { strength, } \varepsilon_{b c},\end{array}$ & 0.047 \\
\hline Ultimate strain, $\varepsilon_{b u u}$ & 0.003 & Ultimate strain, $\varepsilon_{b c u}$ & 0.06 \\
\hline
\end{tabular}

Table 3: $\quad$ Wall and coupling beam steel material properties.

\begin{tabular}{|l|c|l|c|}
\hline \multicolumn{2}{|c|}{ Wall and beam mild steel bars } & \multicolumn{2}{c|}{ Wall base region spiral wire } \\
\hline Yield strength, $f_{s v}$ & $414 \mathrm{MPa}$ & Yield strength, $f_{s w v}$ & $414 \mathrm{MPa}$ \\
\hline Yield strain, $\varepsilon_{s y}$ & 0.00207 & Yield strain, $\varepsilon_{s w y}$ & 0.00207 \\
\hline Maximum strength, $f_{s m}$ & $672 \mathrm{MPa}$ & Maximum strength, $f_{s w u}$ & $621 \mathrm{MPa}$ \\
\hline $\begin{array}{l}\text { Strain at maximum } \\
\text { strength, } \varepsilon_{s u}\end{array}$ & 0.06 & $\begin{array}{l}\text { Strain at maximum } \\
\text { strength, } \varepsilon_{s w u}\end{array}$ & 0.08 \\
\hline
\end{tabular}

Table 4: $\quad$ Beam post-tensioning strands.

\begin{tabular}{|l|c|}
\hline Yield strength, $f_{b p y}$ & $1689 \mathrm{MPa}$ \\
\hline Yield strain, $\varepsilon_{b p y}$ & 0.0086 \\
\hline Maximum strength, $f_{b p u}$ & $1862 \mathrm{MPa}$ \\
\hline $\begin{array}{l}\text { Strain at maximum } \\
\text { strength, } \varepsilon_{b p u}\end{array}$ & 0.05 \\
\hline
\end{tabular}

\subsection{Analytical modelling}

A fibre-element analytical model of the multi-story unbonded post-tensioned precast concrete coupled wall system was developed using previously validated subassembly models (Weldon and Kurama [11]). The DRAIN-2DX (Prakash et al. [18]) computer program serves as the analytical platform for this investigation. Figure 3(a) shows the prototype analytical model for the eightstory prototype coupled wall system. Note that for clarity purposes all the nodes are not shown. 


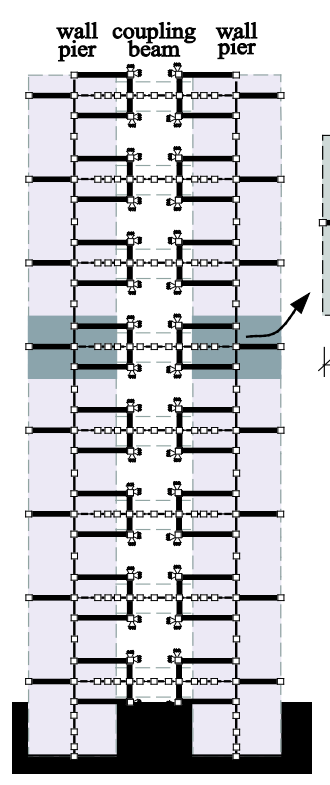

(a)

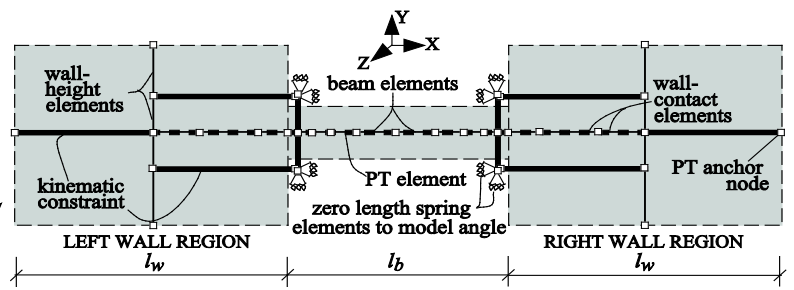

(b)

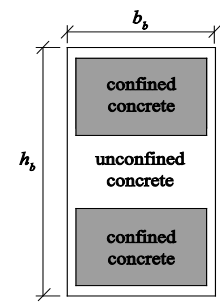

(c)

Figure 3: Analytical model (a) multi-story model (adapted from Shen et al. [16]); (b) floor-level subassembly; (c) cross-section fibre distribution.

Each fibre is defined by a material stress-strain relationship, the fibre's crosssectional area, and its distance from the longitudinal reference axis of the element. As an example, the fibre discretization for the coupling beam crosssection is shown in Figure 3(c). Smaller fibre thicknesses were used near the corners of the coupling beam where the large compressive stresses and nonlinear behaviour is expected to concentrate.

Fibre beam-column elements are used to represent the coupling beams and wall piers (Figure 3(b)). To capture the axial-flexural and shear behaviour of the wall region along its height, "wall-height" elements are modelled in the vertical direction. "Wall-contact" elements, located to the left and right of the coupling beams, are modelled in the horizontal direction. The local behaviour and deformation of the wall concrete due to the large compressive stresses that develop in this region are captured by the "wall-contact" elements. The precast coupling beam is represented by fibre beam-column elements that capture the axial-flexural and shear behaviour of the coupling beams. The post-tensioning tendons are modelled at each floor level using truss elements that extend through the entire length of the walls and beam and are connected only at the outer ends of the walls. The top and seat angles are modelled using a zero-length translational spring element that represent the axial (i.e., lateral direction) force in the horizontal leg of the angle. Full details of the analytical model are described in Aragon and Weldon [19]. 


\section{Behaviour under monotonic static lateral loading}

This section discusses the behaviour of the unbonded post-tensioned coupled wall system under monotonic static loading using the analytical model discussed above. To understand how the behaviour of the system can be controlled by design, different structural parameters are varied and the results are presented

\subsection{Parametric analysis}

Table 5 shows the parameters that were varied in the multi-story model. System (1) is the prototype system presented above (i.e., the baseline). The parameters in systems (2) and (3) are varied one at a time as shown in Table 5 with all other structural properties remaining the same as the baseline system

Table 5: $\quad$ Parametric systems.

\begin{tabular}{|c|c|c|c|}
\hline Parameter varied & $\begin{array}{l}\text { System (1) } \\
\text { [baseline] }\end{array}$ & System (2) & System (3) \\
\hline Beam depth, $h_{b}$ & $711 \mathrm{~mm}$ & $508 \mathrm{~mm}$ & $914 \mathrm{~mm}$ \\
\hline Beam length, $l_{b}$ & $2286 \mathrm{~mm}$ & $1829 \mathrm{~mm}$ & $2743 \mathrm{~mm}$ \\
\hline Beam PT tendon area, $a_{b p t}$ & $1680 \mathrm{~mm}^{2}$ & $1120 \mathrm{~mm}^{2}$ & $2240 \mathrm{~mm}^{2}$ \\
\hline Top and seat angle thickness, $t_{a}$ & $12.7 \mathrm{~mm}$ & $19 \mathrm{~mm}$ & $25.4 \mathrm{~mm}$ \\
\hline $\begin{array}{l}\text { Initial beam PT tendon stress } \\
\text { (per strand), } f_{b p i} \\
\text { Beam depth, } h_{b} \\
\text { (constant initial stress, } f_{b c i} \text { ) }\end{array}$ & $\begin{array}{l}931 \mathrm{MPa} \\
711 \mathrm{~mm}\end{array}$ & $\begin{array}{c}665 \mathrm{MPa} \\
508 \mathrm{~mm}\end{array}$ & $\begin{array}{c}1197 \mathrm{MPa} \\
914 \mathrm{~mm}\end{array}$ \\
\hline Wall length, $l_{w}$ & $4.88 \mathrm{~m}$ & $3.66 \mathrm{~m}$ & $5.49 \mathrm{~m}$ \\
\hline Wall thickness, $t_{w}$ & $355.6 \mathrm{~mm}$ & $254 \mathrm{~mm}$ & $457.2 \mathrm{~mm}$ \\
\hline
\end{tabular}

\subsection{Base shear versus roof $\mathrm{drift}$ behaviour}

The results from the parametric analysis are shown in Figures 4(a)-(g). The base shear versus roof drift (F- $\Delta$ ) relationship of the each system under combined gravity and monotonic lateral loads is presented. The roof drift is defined as the roof lateral displacement at the centreline of the coupled wall system divided by the structure's height $h_{w}$. The base shear is the summation of the shear at the base of both the left and right walls. The lateral load is applied from left to right and applied at each floor level and the roof. A triangular distribution of lateral loads is distributed over the height of the structure and the load is assumed to be equally divided between the left and the right walls.

The structures go through the following states they are displaced laterally: (1) decompression [ $\downarrow$ symbol] (defined as the state when gap opening is initiated); (2) tension side wall softening [ $\bigcirc$ symbol] (defined as the state when the neutral axis at the base of the tension-side wall reaches the centreline of the wall); (3) compression side wall softening [ $\diamond$ symbol]; (4) beam cover concrete crushing $[\square$ symbol]; (5) tension angle yielding [ $\Delta$ symbol]; (6) tension angle ultimate strength [ $\star$ symbol] (defined as when the force in the tension angles 
reaches the full angle tension strength); (7) first beam post-tensioning tendon yielding [ $\triangle$ symbol] (note that the use of unbonded strands significantly delays the yielding of the PT steel, and in a properly designed system, this state will not be reached); (8) compression side wall concrete crushing [X symbol]. Beam confined concrete crushing and angle fracture are also failure states that could be considered; however, these states are expected to be reached, as observed in Weldon and Kurama [10], at larger roof drifts than those presented in the following results.

By varying the structural properties, the results show that the response of the unbonded post-tensioned coupled wall system under lateral loading can be controlled. For example, the lateral strength of the structure is significantly increased as the length of the wall, the depth of the beam, and the thickness of the wall are increased. By decreasing the angle thickness, the beam depth, the wall length, or the amount of post-tensioning or increasing the beam length or wall thickness, the ductility of the system is increased along with delaying crushing of the concrete at the base of the wall. These parameters can be combined (e.g., beam depth and initial post-tensioning stress, Figure 4(e)) to achieve the desired requirements for strength and ductility. It is important to note that the roof drifts in all of the parameter variations presented go beyond the expected design limit states.

\section{Conclusions}

This paper uses previously validated fibre-element analytical subassembly models for unbonded post-tensioned precast concrete coupling beams to develop a multi-story model. The structure's response under monotonic lateral loading is then investigated and a parametric study is conducted to show how the strength and stiffness of the structure can be controlled.

The proposed system offers many advantages including:

1. The coupled wall system can provide significant lateral stiffness, strength, and ductility for structures in seismic regions.

2. The beam depth and length, post-tensioning area, angle thickness, wall length and thickness can be varied to control the structure's response in order to meet the building's lateral strength and stiffness requirements.

3. Stable levels of coupling can be achieved by the post-tensioned concrete beams similar to the levels achieved using a post-tensioned steel beam. The post-tensioning in the system and the opening of gaps at the beamto-wall interfaces result in little damage occurring in the coupling beams and walls.

4. Residual displacements are decreased as a result of the post-tensioning force which provides a restoring force to the walls upon unloading. This results in a large self-centring capability of the system.

5. The proposed system can be used in new construction and, as the beam is independent of the walls (i.e., reinforcement steel does not cross beamto-wall interface), the system has the potential to be used in the seismic retrofit and strengthening of existing concrete walls. 


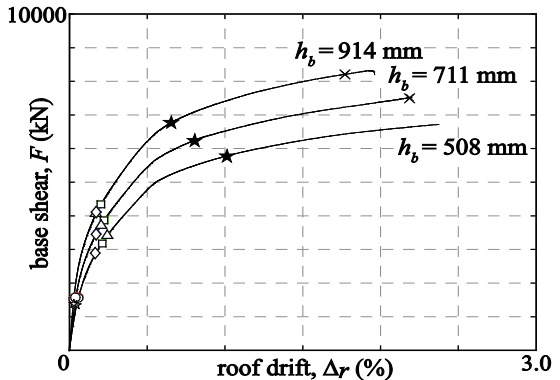

(a)

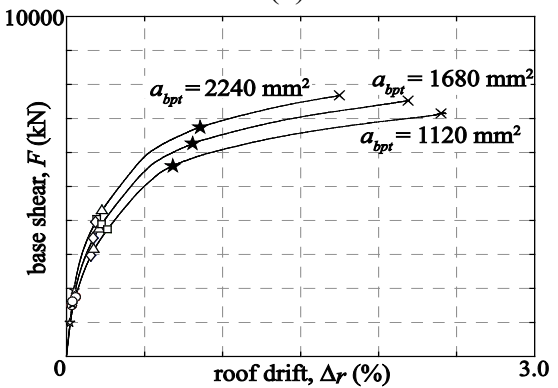

(c)

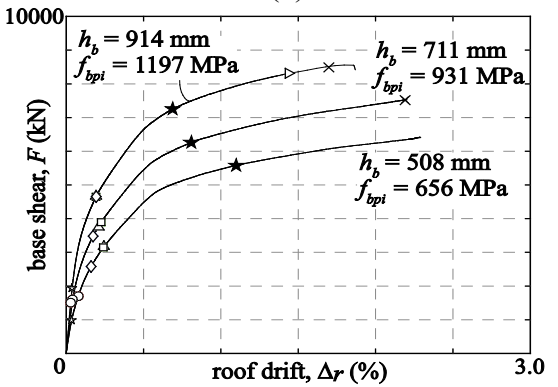

(e)

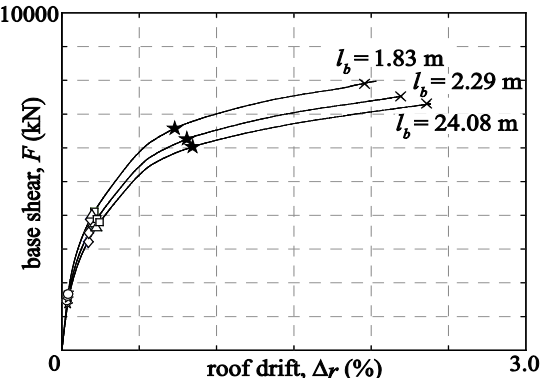

(b)

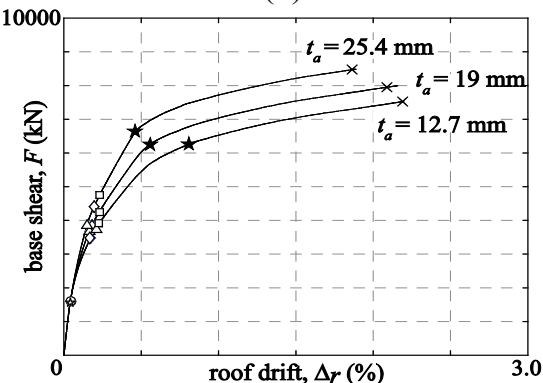

(d)

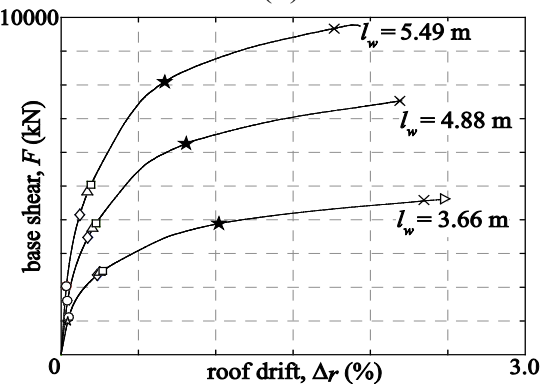

(f)

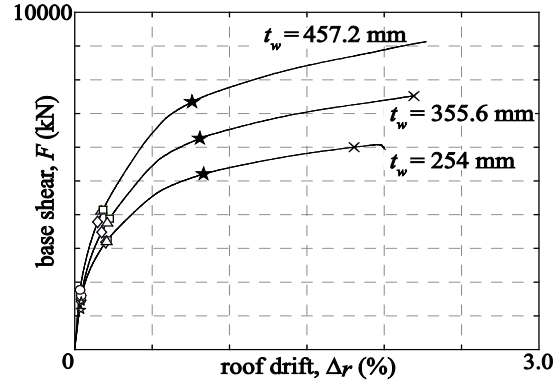

(g)

Figure 4: $\quad$ Parametric study: (a) $h_{b}$; (b) $l_{b}$; (c) $a_{b p t}$; (d) $t_{a}$; (e) $f_{b p i}$ and $h_{b}$; (f) $l_{w}$; (g) $t_{w}$. 
To expand upon the results in this paper and investigate the system further, additional lateral load analyses will be conducted (e.g., reversed cyclic loading and ground motions). To estimate the nonlinear behaviour and limit states of the multi-story coupled wall system, a performance-based seismic evaluation will be investigated for comparison with the analytical results. The results from these analyses will be used in the development of seismic design guidelines and design tools for multi-story unbonded post-tensioned precast concrete coupled walls.

\section{Acknowledgements}

This material is based upon work supported by the National Science Foundation Graduate Research Fellowship under Grant No. DGE-1144468. Any opinion, findings, and conclusions or recommendations expressed in this material are those of the author(s) and do not necessarily reflect the views of the National Science Foundation.

\section{Reference}

[1] Harries, K., Gong, B., and Shahrooz, B., Behavior and design of reinforced concrete, steel, and steel-concrete coupling beams. Earthquake Spectra, 16(4), pp. 775-799, 2000.

[2] Paulay, T. and Binney, J., Diagonally reinforced coupling beams of shear walls. Shear in Reinforced Concrete, American Concrete Institute 2(SP42), pp. 579-598, 1974.

[3] Gong, B. and Shahrooz, B., Steel/Composite coupling beams - behaviour and design. Proc. Of the $4^{\text {th }}$ Joint Technical Coordination Committee Meeting, U.S.-Japan Cooperative Earthquake Research Program on Composite Hybrid Structures, Monterey, CA, 20 pp. 1997.

[4] Kurama, Y.C. and Shen, Q., Seismic design and response evaluation of unbonded post-tensioned hybrid coupled wall structures. Earthquake Engineering and Structural Dynamics, 37, pp. 1677-1702, 2008.

[5] Shen, Q., Kurama, Y., and Weldon, B., Seismic design and analytical modeling of posttensioned hybrid coupled wall subassemblages. Journal of Structural Engineering, ASCE, 132(7), pp. 1030-1040, 2006.

[6] Kurama, Y., Shen, Q., and Weldon, B., Coupling of RC walls using unbonded posttensioning: Applications in hybrid construction. Proc. of the $13^{\text {th }}$ World Conference on Earthquake Engineering, Earthquake Engineering Research Institute, Vancouver, B.C., Canada, Paper No. 3214, 2004.

[7] Kurama, Y.C. and Shen, Q., Posttensioned hybrid coupled walls under lateral loads. Journal of Structural Engineering, ASCE, 130(2), pp. $297-$ 309, 2004.

[8] Shen, Q., and Kurama, Y., Nonlinear behavior of post-tensioned hybrid coupled wall subassemblages. Journal of Structural Engineering, ASCE, 128(10), pp. 1290-1300, 2002. 
[9] Weldon, B. and Kurama, Y., Analytical modeling and design validation of post tensioned precast concrete coupling beams for seismic regions. Journal of Structural Engineering, ASCE, 138(2), pp. 224-234, 2012.

[10] Weldon, B.D. and Kurama, Y., Experimental evaluation of post-tensioned precast concrete coupling beams. Journal of Structural Engineering, ASCE 136(9), pp. 1066-1077, 2010.

[11] Weldon, B.D. and Kurama, Y., Seismic analysis, behavior, and design of unbonded post-tensioned precast concrete coupling beams. Structural Engineering Research Report. \#NDSE-10-01, Dept. of Civil Engineering \& Geological Sciences, University of Notre Dame, Notre Dame, IN., 2010.

[12] Weldon, B. and Kurama, Y., Nonlinear behavior of precast concrete coupling beams under lateral loads. Journal of Structural Engineering, ASCE, 133(11), pp. 1571-1581, 2007.

[13] Shen, Q., Kurama, Y., and Weldon, B., Seismic analysis, behavior, and design of unbonded post tensioned hybrid coupled walls. Structural Engineering Research. Report. \#NDSE-05-01, Department of Civil Engineering and Geological Sciences, University of Notre Dame, Notre Dame, IN., 2006.

[14] Mander, J., Priestley, M., and Park, R., Theoretical stress-strain model for confined concrete. Journal of Structural Engineering, ASCE, 114(8), pp. 1804-1826, 1988.

[15] Paulay, T. and Priestley, M., Seismic design of reinforced concrete and masonry buildings. John Wiley \& Sons, Inc., 744 pp. 1992.

[16] Kishi, N. and Chen, W., Moment-rotation relations of semirigid connections with angles. Journal of Structural Engineering, ASCE, 116(7), pp. 1813-1834., 1990.

[17] Lorenz, R., Kato, B., and Chen, W., Semi-rigid connections in steel frames. Council on Tall Buildings and Urban Habitat, Comm. 43, McGraw-Hill, Inc., 1993.

[18] Prakash, V., Powell, G., and Campbell, S., DRAIN-2DX base program description and user guide. Version 1.10. Rep. No. UCB/SEMM-93/17, Dept. of Civil Engineering, University of California, Berkeley, CA., 1993.

[19] Aragon, T. and Weldon, B., Non-linear behaviour of multi-story walls using unbonded post-tensioned concrete coupling beams. Proc. of Structures Congress, ASCE, Pittsburgh, PA, 12 pp. 2013. 